\title{
SOSIALISASI TEKNOLOGI FISSION SEBAGAI ALTERNATIF PEMBIAKAN TERIPANG (Holothuria sp) BAGI MASYARAKAT SIMEULUE ACEH
}

\author{
Zulfadhli $^{1 *}$, Burhanis $^{2}$, Edwarsyah ${ }^{3}$ \\ 1 Program Studi Akuakultur, Fakultas Perikanan dan IImu Kelautan, Universitas Teuku Umar \\ 2 Program Studi IImu Kelautan, Fakultas Perikanan dan IImu Kelautan, Universitas Teuku Umar \\ 3 Program Studi Sumber Daya Akuatik, Fakultas Perikanan dan IImu Kelautan, Universitas Teuku Umar \\ *Korepondensi: zulfadhli@utu.ac.id
}

\begin{abstract}
ABSTRAK
Perairan pulau Simeulue dianugrahi oleh sumberdaya alam yang berlimpah, seperti ikan karang, lobster, teripang dan organisme akuatik lainnya. Organisme akuatik selalu jadi target pemburuan nelayan karena memiliki harga jual yang tinggi terutama teripang. Eksplorasi yang berlebihan membuat populasi teripang di alam menurun dan terancam kelestarianya. Produksi budidaya teripang masih rendah karena benih diperoleh dari alam dan kegiatanya dilakukan secara tradisional. Pengetahuan nelayan juga rendah dalam hal pembiakan teripang. Disisi lain pembiakan teripang secara seksual membutuh fasilitas dan biaya operasional yang tinggi. Solusi yang diberikan adalah pembiakan teripang secara aseksual dengan teknologi fission. Teknologi ini sangat sederhana tanpa perlu fasilitas canggih, mudah di pahami oleh masyarakat dan biaya operasional murah. Tujuan kegiatan ini adalah memberikan edukasi terhadap masyarakat simeulue. Transfer Iptek ini dilakukan kepada nelayan/masyarakat dengan metode sosialisasi pelestarian teripang dan teknik fission. Masyarakat antusias dalam mengikuti sosialisasi dan adanya peningkatan pengetahuan/wawasan baru tentang Teknik fission dan kesadara dalam menjaga kelestarian teripang di alam.
\end{abstract}

Kata Kunci: fission, pembiakan, teripang, simeulue

\section{PENDAHULUAN}

Pulau Simeulue dengan ibu kota Sinabang merupakan pulau terdepan Indonesia yang berada di wilayah barat selatan Provinsi Aceh dan berhadapan langsung dengan samudera hindia. Luas kabupaten Simeulue $183.809 \mathrm{Ha}$ dan curah hujan mencapai 3761mm/tahun. Kabupaten ini memiliki 10 kecamatan, 29 mukim, 138 desa dan 411 dusun dengan jumlah penduduk sebanyak 90.291 jiwa. Letak yang jauh dengan ibu kota menyebabkan sebagian desa di kabupaten ini masih tertinggal. Sebanyak 72 desa dalam katagori tertinggal dan 14 desa statusnya sangat tertinggal (BPS, 2017).

Pulau Simeulue memiliki sumberdaya perairan yang melimpah. Banyak dijumpai berbagai jenis ikan, echinodermata, bivalvia, udang dan biota akuatik lainnya. Melimpahnya keanekaragaman dari biota laut dimanfaatkan oleh penduduk setempat untuk ditangkap karena mempunyai nilai ekonomis tinggi. Beberapa jenis biota yang ditangkap meliputi ikan, udang, teripang, cumi-cumi dan kerang-kerangan. Salah satu biota perairan yang banyak ditangkap dari habitat alam adalah teripang (Holothuria sp).

Teripang atau sea cucumber telah banyak dimanfaatkan sebagai bahan baku makanan dan obat-obatan (Pangkey dkk., 2012). Masyarakat Simeulue memanfaatkan teripang sebagai produk khas/oleh-oleh dari Pulau Simeulue, seperti: kerupuk teripang, minyak teripang dan produk lainnya. Harga teripang kering di pasar lokal Indonesia berkisar Rp. 600.000/kg (Tatalede dan Salindeho, 2018) dan dipasar internasional harga teripang pasir rata-rata berkisar Rp. 4.250.000/kg (Robinson and Lovatelli, 2015). Harga yang tinggi mengakibatkan intensitas penangkapan teripang di habitat alam pun tinggi. Tingginya intensitas penangkapan menyebabkan populasi teripang 
semakin menurun. Kondisi ini berpengaruh terhadap ekonomi nelayan yang mengantung kehidupannya pada usaha teripang.

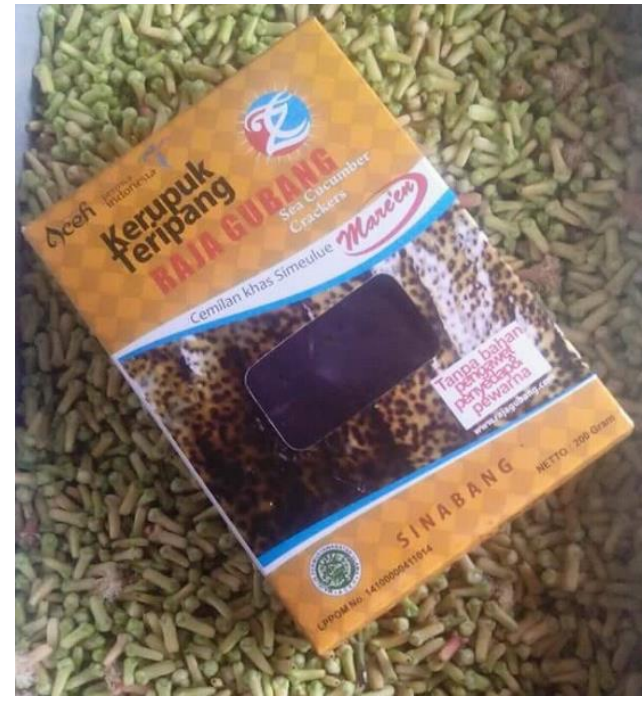

(a)

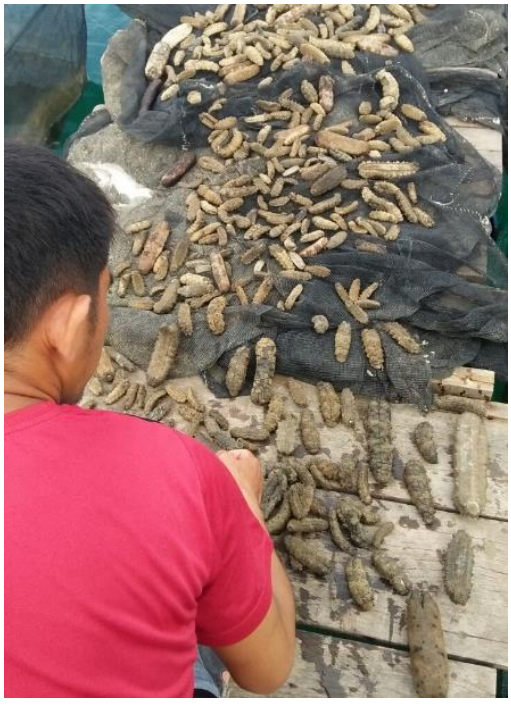

(b)

Gambar 1. Kerupuk teripang (a), teripang kering (b) di pulau Simeulue

Teripang memberikan banyak manfaat bagi masyarakat nelayan. Pertumbuhan ekonomi meningkat dengan adanya usaha pengolahan teripang dan agen pengumpul teripang kering di Pulau Simeulue. Disisi lain, Alam tidak mampu mengkompensasi intensitas penangkapan teripang yang tinggi. Oleh karena itu, diperlukan sebuah solusi yang tepat dimana nelayan dapat memanfaatkan teripang untuk keperluan ekonomi dan populasi teripang juga terjaga.

\section{Permasalahan}

Permintaan teripang dengan harga tinggi membuat para nelaya terus menerus menangkap teripang di alam. Tanpa di sadari secara langsung, hasil tangkapan teripang setiap waktu mengalami penurunan akibat populasi teripang yang semakin sedikit. Usaha budidaya benih teripang dari alam juga mengalami masalah yaitu benih hanya diperoleh pada musim tertentu dengan jumlah yang terbatas. Nelayan memiliki keinginan untuk usaha budidaya teripang tapi terkendala dengan induk dan pengetahuan budidaya teripang yang rendah. Di Indonesia pembiakan teripang sudah dikuasai namun masih sangat terbatas dan terkendala dalam hal tingkat kelangsungan hidup benih yang rendah. Pembiakan dilakukan secara seksual, dimana terjadi peleburan sel sperma dengan sel telur. Selain itu pembiakan secara seksual memerlukan fasilitas yang canggih dan biaya operasional yang tinggi, sehingga tidak memungkinkan pembiakan teripang secara seksual dilakukan. Pertimbanganya adalah nelayan ekonomi rendah sulit mengakomodasi biaya operasional tinggi dan menyiapkan fasilitas canggih, kemudian nelayan berada di wilayah pulau terdepan indonesia yang jauh dengan akses kota.

\section{Solusi Penyelesaian masalah}

Berdasarkan permasalahan yang dihadapi, solusi yang ditawarkan yaitu pembiakan teripang dengan teknologi fission. Teknologi fission merupakan teknologi pembiakan secara aseksual (pembelahan) dengan pemberian stimulus (rangsangan) buatan. Keuntungan 
pembiakan teripang dengan teknologi fission, yaitu: 1).Teknologinya sederhana sehingga mudah dipahami dan dilakukan oleh nelayan, 2).Tidak memerlukan fasilitas canggih sehingga biaya operasional minim, 3).Pertumbuhan dan produksinya lebih cepat karena dimulai dari ukuran yang lebih besar, bila dibandingkan dengan larva hasil pembiakan secara seksual, 4).Individu teripang hasil fission tidak melewati masa larva dan juvenile sehingga terhindar dari fase kritis. kehidupan larva teripang diketahui relative lama mencapai 1-2 bulan dan sangat rentan kehidupannya bila lingkungan tidak sesuai. 5).Teripang hasil fission secara langsung beradaptasi dilingkungan induknya sehingga tidak perlu dipindahkan dan tidak perlu tempat khusus, cukup di habitat alami.

\section{METODE PELAKSANAAN}

Metode pelaksanaan dilakukan dengan cara sosialisasi, dengan memberikan wawasan/pengetahuan tentang menjaga kelestarian teripang di alam dan budidaya teripang menggunakan teknologi fission.

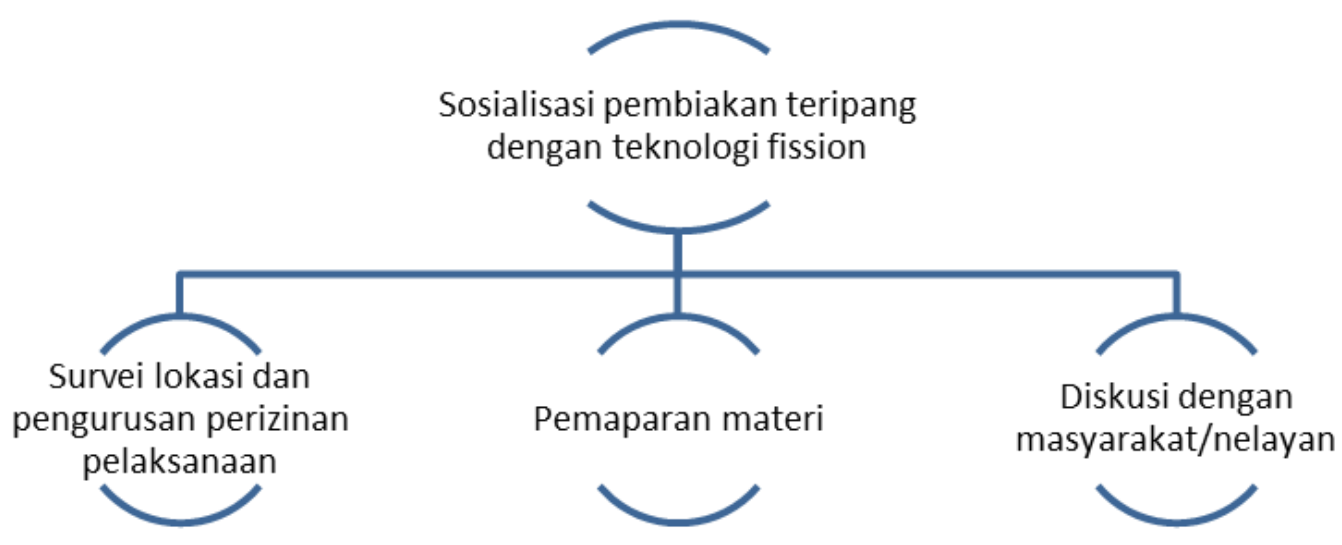

Gambar 2. Tahapan pelaksanaan

Sosialisasi dilakukan untuk memberikan edukasi pada masyarakat Simeulue. Kegiatan ini akan berlangsung dengan pemaparan materi oleh tenaga ahli tentang pengelolaan teripang untuk menjaga kelestariaanya di alam dan pemaparan materi tentang teknologi fission. Kemudian di lanjutkan dengan diskusi interaktif antara pemateri dengan nelayan/masyarakat. Tujuan sosialisasi ini diberikan agar nelayan mendapatkan pengetahuan dan wawasan baru dalam pembiakan teripang dengan teknologi fission. Nelayan juga akan di edukasi bagaimana menjaga dan memulihkan populasi teripang di alam. Peserta yang mengikuti sosialisasi diharapkan dapat menggerakkan masyarakat lain untuk bersama-sama menjaga kehidupan laut. Pada saat sosialisasi juga diundang panglima laut sehingga nelayan dapat bersama-sama membuat sebuah aturan terkait penangkapan teripang di alam. 


\section{HASIL DAN PEMBAHASAN}

Sosialisasi pembiakan teripang menggunakan teknologi fission dilaksanakan Desa Suka Karya Kecamatan Simeulu Timur Kabupaten Simeulue. Peserta yang mengikuti sosialisai berjumlah 24 orang dari kelompok nelayan dan masyarakat umum.
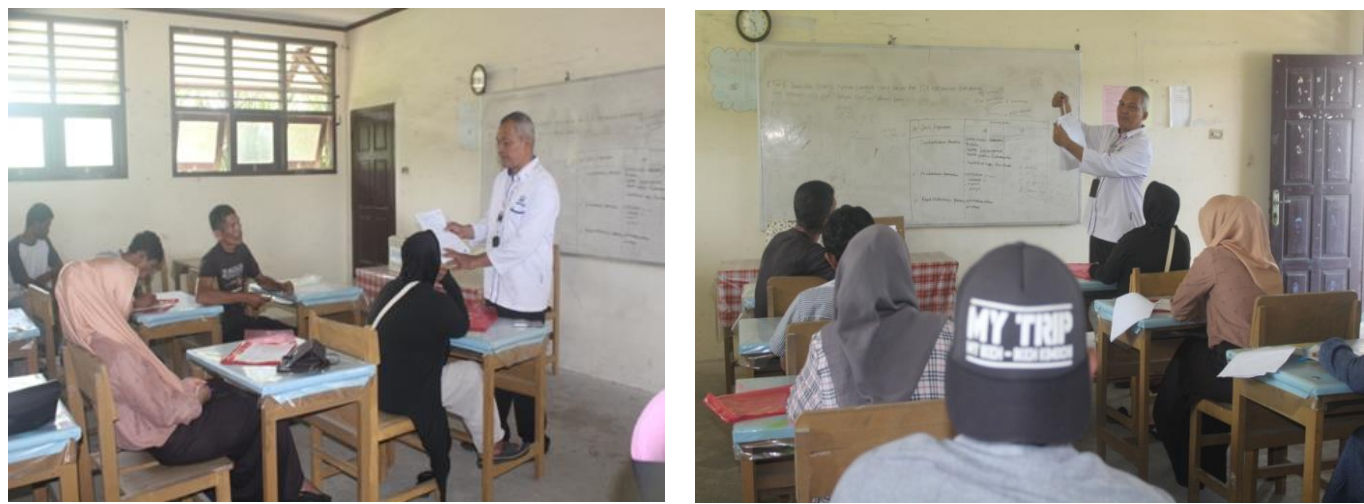

Gambar 3. Dokumentasi pelaksanaan

Ouput dari sosialisasi ini adalah memberikan pemahaman dan pengetahuan terhadap nelayan/masyarakat tentang pembiakan teripang menggunakan teknologi fission. Selain itu, juga diberikan materi tentang bagaimana cara menjaga kelestarian sumberdaya teripang di alam, seperti penentuan musim tangkap teripang dan ukuran teripang yang boleh di tangkap. Materi yang diberikan dalam sosialisasi yaitu:

Tahapan pembiakan aseksual teripang dengan teknik fission

a. Persiapan bahan dan alat

Bahan dan alat yang digunakan sederhana dan mudah diperoleh, yaitu teripang dewasa, karet pentil, baskom, keranjang plastik berukuran $20 \times 40 \times 10 \mathrm{~cm}^{3}$, waring, tali ,kayu, batu, dan keramba tancap.

b. Teknik perangsangan (pengikatan teripang)

Sebelum pengikatan terlebih dahulu dilakukan pengamatan tubuh teripang dengan melihat bagian anterior dan posterior. Pengikatan tubuh teripang dengan karet pentil dilakukan pada bagian tengah tubuh, dengan jarak pengikatan 1/3 dari bagian anterior. Langkah kerja proses penikatan adalah:

$>$ Teripang diambil dan dimasukkan kedalam baskom yang sudah terisi 5 liter air laut.

> Isi satu ekor teripang dan satu buah karet pentil dalam wadah (baskom)

$>$ Ambil karet pentil lalu ikat bagian tubuh teripang dengan jarak 1/3 dari bagian mulut (anterior)

$>$ Usahakan ikatan kuat dan kencang untuk meminimalkan karet telepas dari tubuh teripang

$>$ Setelah berhasil diikat, teripang dipindahkan dan dipelihara dalam keranjang plastik berukuran $20 \times 40 \times 10 \mathrm{~cm}^{3}$

$>$ Teripang yang diikat akan mengalami proses pembelahan sehingga bagian anterior (mulut) dan posterior (anus) berpisah dan menjadi dua individu teripang. Proses pembelahan akan memakan waktu berkisar 6-12 jam.

c. Pemeliharaan

Teripang yang sudah berhasil melakukan pembelahan dipindahkan ke dalam keramba jaring tancap. Lokasi pemeliharaan dipinggir laut dengan parameter kualitas air yang baik. Menurut Widianingsih dkk (2014), perairan yang layak 
untuk budidaya teripang yaitu: 1).Memiliki kecerahan sampai dasar perairan, 2).Salinitas perairan $>30 p p t$ dan memiliki suhu perairan berkisar 27-30oC, 3).Subtrat perairan berpasir dan banyak tumbuh lamun/rumput laut, 4).Kondisi perairan tenang dan terbebas dari ombak besar. Pemeliharaan meliputi penutupan luka dan pembesaran untuk tumbuh. Bagian dinding tubuh yang terbelah akan mengalami regenerasi atau penutupan luka. Penutupan luka akan mengerucut pada satu bagian dan nantinya bagian ini akan membentuk mulut dan anus baru.

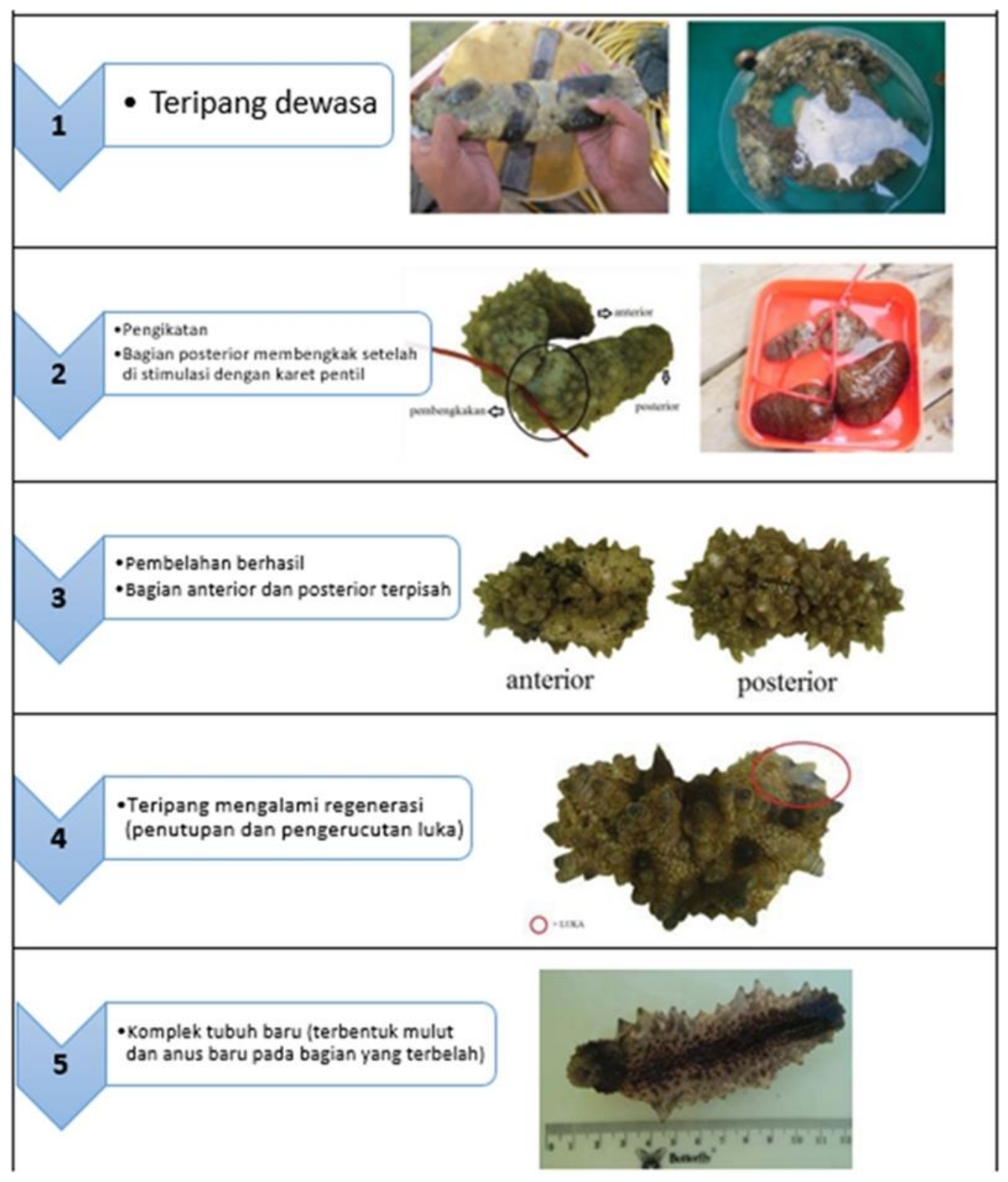

Gambar 4. Tahap pembiakan aseksual teripang dengan teknik fission 


\section{SIMPULAN DAN SARAN}

Masyarakat mendapatkan pengetahuan tentang teknologi fission dan wawasan pentingnya menjaga kelestarian sumberdaya alam teripang. kedepan direncanakan akan melaksanakan pelatihan/pendampingan secara langsung di lapangan.

\section{DAFTAR PUSTAKA}

BPS. 2017. Statistik Kabuapten Simeulue tahun 2017. Penerbit BPS dan Diskominfosandi Kabupaten Simeulue. ISBN: 978-602-71108-1-6. Sumber: http://simeuluekab.go.id/index.php/document/download/205/stastistikkabupaten-simeulue-tahun-2017.html diakses 30 Agustus 2018.

Pangkey, H., Lantu, S., Manu, L., and Mokolensang, J.F. 2012. Prospect of Sea Cucumber culture in Indonesia as potential food sources. Journal of Coastal Development. 15: 114 - 124.

Robinson, G., and Lovatelli, A. 2015. Global sea cucumber fisheries and aquaculture FAO's inputs over the past few years. FAO Aquaculture Newsletter. 53-57 hal.

Tatalede, P.A, dan Salindeho, I.R.N. 2018. Tingkat keberhasilan hidup teripang gamat lumpur, Stichopus hermanni, hasil dari transverse fission. Budidaya Perairan. $6(2): 7-16$.

Widianingsih, Hartati, R., dan Endrawati, H. 2014. Penerapan Teknologi Fisson Pada Budidaya Teripang. Majalah Info. 16 (2): 59-71. 